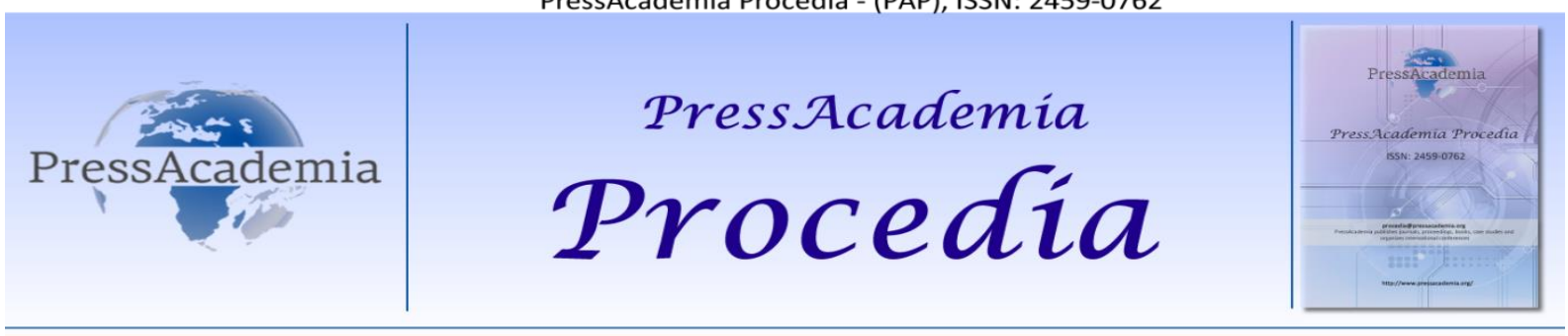

Global Business Research Congress (GBRC), May 24-25, 2017, Istanbul, Turkey

\title{
THE IMPORTANCE OF INNOVATIVE APPROACHES IN NURSING
}

\section{DOI: 10.17261/Pressacademia.2017.655}

PAP- GBRC-V.3-2017(81)-p.759-761

\author{
Sureyya Gumussoy ${ }^{1}$, Gulseren Keskin ${ }^{2}$, Gul Ozlem Yiidirim ${ }^{3}$, Elif Aktekin ${ }^{4}$ \\ ${ }^{1}$ Ege University Atatürk Healthcare Vocational School, Bornova/izmir, Türkiye. sureyya.gumussoy@ege.edu.tr \\ ${ }^{2}$ Ege University Atatürk Healthcare Vocational School, Bornova/izmir, Türkiye. gulseren.keskin@ege.edu.tr \\ ${ }^{3}$ Ege University Atatürk Healthcare Vocational School, Bornova/izmir, Türkiye. gulozlemy@yahoo.com \\ ${ }^{4}$ Ege University Atatürk Healthcare Vocational School, Bornova/Izmir, Türkiye. elif aktekin@hotmail.com
}

To cite this document

Gumussoy, S., G. Keskin, G.O. Yildirim, E. Aktekin, (2017). The importance of innovative approaches in nursing. PressAcademia Procedia (PAP), V.3, p.759-761.

Permemant link to this document: http://doi.org/10.17261/Pressacademia.2017.655

Copyright: Published by PressAcademia and limited licenced re-use rights only.

\begin{abstract}
With this study, it is aimed to review the innovative approaches in nursing education and practices. The articles on innovation in nursing, which are included in various databases, have been exploited by relevant key words and studies that are appropriate for oversight. Nursing services in order to provide planning, strategies and Innovation, the use of the service quality is among important factors that affect directly. Because nurses are responsible for knowing what they are doing and why they are doing while offering complex and important services such as patient care in the existing health care system. At the same time, nurses take responsibility for being a more efficient, higher-quality and cost-effective, when their services are given how and in which ways. Changing and evolving health care system, people basic health needs of people, and therefore also affect the nursing education. Nurses are required to keep pace with development and change in order to achieve effective and desired results when delivering services and to combine innovative approaches with their services. For this reason, the concepts of simulation, technology and knowledge should be integrated into the content of vocational training. Nurse managers should facilitate the creative efforts of teaching staff in their teaching and clinical practice and innovative programs.
\end{abstract}

Keywords: nursing education, nursing management, innovative approaches, nursing practices, innovation JEL Codes: J10, J12, J15

\section{HEMŞiRELIK MESLEĞiNDE YENILIKÇi YAKLAŞIMLARIN ÖNEMi}

\section{ÖZET}

Bu çalışma ile hemşirelik eğitimi ve uygulamalarında gerçekleştirilen yenilikçi yaklaşımların gözden geçirilmesi amaçlanmaktadır. Çeşitli veri tabanlarında yer alan, hemşirelikte inovasyon ile ilgili makaleler, ilgili anahtar kelimeler ile taranmış ve gözden geçirme için uygun olan çalışmalardan yararlanılmıştır. Hemşirelik eğitimlerini ve hasta bakım hizmetlerini planlamak, sunmak ve değerlendirmek için yenilikçi stratejilerin kullanılması, sağlık profesyonelleri olan hemşirelerin vereceği bakımın kalitesini direkt etkileyen önemli faktörlerdendir. Çünkü hemşireler, mevcut sağılı sistemi bünyesinde hasta bakımı gibi ehemmiyetli ve aynı zamanda karmaşık bir hizmet sunarken neyi neden yaptıklarını ve yapılan uygulamaların bilimsel dayanağını bilmeli, sorgulamalı, verilen hizmetin ne şekilde ve nasıl uygulandığında daha etkin, kaliteli ve ekonomik olacağını da araştırmanın sorumluluğunu taşımaktadırlar. Sürekli değişen ve aynı zamanda gelişim gösteren sağlık sistemi, hem insanların temel sağlık ihtiyaçlarını hem de hemşirelik eğitimini dolaylı olarak etkileyebilmektedir. Hemşireler hizmet sunumu yaparken etkili ve istenen sonuçları elde edebilmek için sürekli olan gelişime ve değişime ayak uydurmak ve yenilikçi yaklaşımları hizmetleri ile birleştirmek zorundadırlar, bu nedenle simülasyon, teknoloji ve bilişim kavramları meslekler arası eğitim içeriğine entegre edilmeli, hemşire yöneticiler, öğretim üyelerinin eğitim ve klinik uygulamalarında yaratıcı olma çabalarını ve yenilikçi programları kolaylaştırmalıdır.

Anahtar Kelimeler: hemşirelik eğitimi, hemşirelik yönetimi, yenilikçi yaklaşımlar, hemşirelik uygulamaları, inovasyon JEL Kodları: J10, J12, J15 


\section{GíRiş}

İnovasyon, yeni ve değişik bir şey yapmak, yenilik, yenileme manasına gelen Latince "innovare" kelimesinden üretilmiştir. Aynı zamanda inovasyon, bilim ve teknolojinin ekonomiye ve topluma yararlı olabilecek şekilde yenilenmesi, toplumsal, kültürel ve yönetimsel anlamda yeni metotların kullanılması manasına gelmektedir (Bağcı, 2014; Oktay, 2014; Sarıoğlu, 2014). Hızlı bir şekilde değişmekte olan dünyada değişime ayak uydurabilmek, kişisel, kurumsal ve mesleki hayatı devam ettirebilmek için örgütlerin, örgüt yöneticilerinin ve çalışanlarının hatta kişilerin kendilerini devamlı olacak şekilde yenilemeleri ve yenilikçilik anlayışını alışkanlık haline getirmeleri bir gerekliliktir (Bağcı, 2014).

\section{LITERATÜR INCELEMESI}

Son zamanlarda bilimsel kanıta dayalı bilgilerin önemliliği gün geçtikçe artmakta aynı zamanda hastalara uygulanan sağlık bakım metodları değişmektedir (Oktay, 2014). İnovasyonun önemli bir şekilde kullanıldığı hizmetlerin başında sağlık bakımı gelmektedir. Nüfusların yapısındaki değişimler, hastalıkların çeşitlerindeki artma, kronik hastalıkların sayısındaki artış, toplumdaki beklenti artışı gibi bir çok sebep mevcut sağlık sisteminde yeni ihtiyaç ve gereksinimler doğurmakta ve bu gereksinimler neticesinde önemli değişiklikler ortaya çıkmaktadır. Bu değişiklikleri bakım verdiği birey/aile ve topluma ulaştıran sağlık çalışanları arasında en önemli yeri hemşireler tutmaktadır (Sarıŏlu, 2014). Tarihte hemşirelik uygulamalarında küçük ama oldukça önemli inovatif uygulamalar gerçekleştirilmiştir ve bu uygulamalar toplum sağlığının ve sağlık sisteminin düzeltilmesinde önemli gelişmelere sebep olmuştur. 1860 'da Nightingale, ölüm oranlarının en sık hastanede doğum yapan kadınlarda olduğunu belirlemiş ve hasta bakımının önemli olduğunu vurgulayan bu yeni bilgi ile, doğum yapan kadınların hayatları kurtarılmıştır. Kuzey Afrika'da, hemşirelerin HIV/AIDS'li bireylere destek olmak için cep telefonları vasıtasıyla hastalarla iletişime geçerek antiretroviral tedavide bakıma danışman olarak katılması sonucunda hastaların distreslerinin anlamlı derecede azaldığı belirlenmiştir. Amerikalı bir hemşire tarafından geliştirilen kanguru bakımı, toplumsal olarak kabul edilebilir; uygulaması kolay, ekonomik ve oldukça da güvenli bir yöntemdir. Bu yöntemin gelişmekte olan ülkelerde uygulanması ile neonatal ölüm hızının azaldığı saptanmıştır (Şengün, 2016).

\section{VERI VE YÖNTEM}

ProQuest Health \& Medical Complete, MEDLINE, Pubmed, Wiley- Blackwell, ScienceDirect, Web of Science, veri tabanlarında ve Google Akademik'te yer alan hemşirelikte inovasyon ile ilgili makaleler anahtar kelimeler ile taranmış ve gözden geçirme için uygun olan çalışmalardan yararlanılmıştır.

\section{BULGULAR VE TARTIŞMA}

Inovasyon, ülkelerin ekonomik açıdan sürdürülebilir büyümeyi yakalaması, toplumun refahını ve yaşam kalitesini yükseltmesi için önemli araçlardan biridir (Oktay, 2014). Sağlık alanında yeniliklerin sürekli hale gelmesi, hemşirelik mesleği mensuplarını hemşirelik ve hasta bakım uygulamalarında değişikliklere adapte olmaya ve aynı zamanda yenilikleri uygulamaya zorlamaktadır. Hemşireler, işyerlerinde klinik yönergeler, protokoller veya çalışma biçimlerini değiştirme gibi yeniliklerin uygulamaya geçirilmesi gibi durumlarla karşılaşırlar. Yeniliklerin uygulanması hemşirelerin bilgi, beceri ve tutumlarının değişmesini gerektirir (Immermans ve ark, 2013). Uluslararası Hemşireler Birliği (International Council of Nurses=ICN) yenilikçiliği "yeni yaklaşımlar, teknolojiler ve çalışma yolları geliştirme süreci" olarak tanımlamaktadır. Yenilikçilik, aletler, teknolojiler, süreçler için olabileceği gibi bir organizasyon ya da bireyin tutumları, davranışları ve çalışmaları ile ilgili de olabilir (Herdman, 2009). Hemşireler arasında yeniliği teşvik etmek ve geliştirmek için giderek artan bir ilgi vardır. Uluslararası olarak hemşireler, çoğunlukla son derece hassas, karmaşık ve yerleşik toplumsal farklııklar bağlamında bakım vermenin ön safhasındadır. Hemşireler tarafından bakım verilen bireylerin, ailelerin ve toplulukların çoğu savunmasız ve kronik olarak yetersizdir, yani bu hemşirelerin çok çeşitli ortamlarda bakım yapmaya giriştikleri anlamına gelir (Jackson ve ark, 2014). Hemşirelik bakım uygulamalarında son zamanlarda kanıta dayalı uygulamalara önem verilmesi, hemşirelik eğitimi açısından bilginin beceriye daha kolay dönüştürülebilmesi amacıyla eğitimde simülasyon tekniğinin kullanılması, hasta bakım hizmetlerinde standardizasyon ve akreditasyon çalışmalarına ağırlık verilmesi gibi gelişme ve değişimlere önem verilmeye başlanmıştır. Bu önemli çalışmalar, hemşirelerdeki eleştirel düşünce becerilerinin artmasını sağlayarak yapacakları hasta bakım uygulamalarında doğru kararlar vermelerini sağlayacaktır, böylece hemşirelik mesleğinde inovasyon çalışmalarının kolaylaştırılmasının önü açılacaktır (International Council of Nurses, 2009). Sağlıklı olmak insanların en temel intiyaçlarından biri olmakla beraber insanların temel yaşamsal haklarından biridir. Sözkonusu hakların sağlanması ve ihtiyaçların giderilmesinde sağlığın korunması, hastalıkların tedavi ve bakımının yapılması aynı zamanda hastaların tedavi sonrası rehabilitasyonunun sağlanmasının uygulayıcısı olarak görev alan alan hemşirelik mesleğinin, bilim, teknoloji, ekonomi açısından ve sosyal, toplumsal açıdan değişim ve gelişimlerle aynı doğrultuda kendini yenilemesi bir gerekliliktir (ICN, 2009; 2008a; 2008b). ICN'in (2009) raporunda inovasyon, hemşirelik mesleğinin hasta bakım uygulamalarında, insan sağlığııın korunması, hastalıkların önüne geçilmesi, risk faktörlerinin belirlenmesi ve bunların önlenmesi bununla birlikte sağı̆ğı geliştirici uygulamalara önem verilmesi, bakımın daha nitelikli olabilmesi için güncel 
bilgilerin/yöntemlerin/hizmetlerin keşfedilmesinde oldukça önemlidir. Hemşirelikte hastaların bakım hizmetlerinde planlama, uygulama ve değerlendirilmesi konusunda inovatif yöntemlerden yararlanılması, verilecek hizmetteki kaliteyi direkt olarak etkileyen oldukça önem arz eden unsurlar arasındadır. Bu sebepledir ki hemşireler, mevcut sağlık bakım sisteminde hasta bakımı gibi mühim ve kompleks bir hizmeti yerine getirirken neyi hangi sebeple uyguladıklarını ve verdikleri bakım hizmetinin hangi bilimsel temellere dayandığının farkında olmakla birlikte, verdikleri hasta bakım hizmetini devamlı bir şekilde değerlendirerek hizmetin hastalar için hem uygun ve hem de etkili olup olmadığını sorgulamak, aynı zamanda bakım hizmetinin nasıl bir şekilde ve başka hangi yollarla verilirse daha etkin, nitelikli ve daha az maliyetli olabileceğini de araştırma sorumluluğu taşımaktadırlar (Dil ve ark. 2012).

\section{SONUC}

Hemşireler hizmet sunumu yaparken etkili ve istenen sonuçları elde edebilmek için sürekli olan gelişime ve değişime ayak uydurmak ve yenilikçi yaklaşımları hizmetleri ile birleştirmek zorundadırlar, bu nedenle simülasyon, teknoloji ve bilişim kavramları mesleklerarası eğitim içeriğine entegre edilmeli, hemşire yöneticiler, öğretim üyelerinin eğitim ve klinik uygulamalarında yaratıcı olma çabalarını ve yenilikçi programları kolaylaştırmalıdır. Hastalara verilmesi gereken bakım hizmetlerindeki gereksinimlerin belirlenmesi ve bu gereksinimleri karşılamak için hemşirelerin inovatif düşünce ve uygulamalara ve yeniliğe karşı direnç göstermemeleri, yeni düşünceler geliştirebilmeleri ve geliştirilen yeni düşünceleri uygulamaya geçirebilmeleri bununla birlikte inovatör (yenilikçi) rolünü etkin olarak ortaya koymaları bir gerekliliktir (Sarıŏlu, 2014).

\section{KAYNAKLAR}

Bağcı G. (2014). Sağıık Eğitiminde İnovasyon Süreci. İstanbul Şişli Meslek Yüksekokulu Şişli Akademi Dergisi, 2014(01):7-11.

Dil S., Uzun M., Aykanat B. (2012) Hemşirelik eğitiminde inovasyon. International Journal of Human Sciences [Online]. 2012; 2 (9): 12171228.

Herdman E A., (2009) (Çeviri: Yazici Korkmaz Ö.) Hemşirelik ve Yenilikçilik. Hemşirelikte Eğitim ve Araştırma Dergisi 2009; 6 (2): 2-4

International Council of Nurses (2009). Delivering quality, serving communities: Nurses leading care innovations. http://www.icn.ch/publications/2009-delivering-quality- serving-communities-nurses-leading-care-innovations.

International Council of Nurses (2008a). Delivering quality, serving communities: Nurses leading primary health care. International Nurses Day Kit, Geneva.

International Council of Nurses (2008b). Nursing perspectives and contribution to primary health care, Geneva.

Jackson D., Girvin J., DaviDson P M. (2014) Nursing innovation and reform in health care. Contemporary Nurse, 2014;48(2): 130-132.

Oktay Ö. (2014) Uludağ Üniversitesi Tip Fakültesi Hastanesi'nde Görev Yapan Hemşirelerin İnovatif Düşünme Becerilerinin Değerlendirilmesi TC Okan Üniversitesi Sağlik Bilimleri Enstitüsü Sağlik Yönetimi Anabilim Dali Yüksek Lisans Bitirme Projesi İstanbul 2014. (Proje Danışmanı Yrd. Doç. Dr. Yıldırım B. Gülhan)

Sarıoğlu A. (2014) T.C. Atatürk Üniversitesi, Sağlik Bilimleri Enstitüsü Bireysel Yenilikçilik Ölçeğinin Hemşirelikte Geçerlik ve Güvenirliği Hemşirelikte Yönetim Anabilim Dalı Yüksek Lisans Tezi-2014 (Tez Danışmanı Doç.Dr. Serap Altuntaş).

Şengün H. (2016) Sağlık hizmetleri sunumunda inovasyon. Med Bull Haseki 2016;54:194-8. DOI: 10.4274/haseki.3057

Immermans O., Van Linge R., Van Petegem P., Van Rompaey B., Denekens J. (2013) A contingency perspective on team learning and innovation in nursing. Journal of Advanced Nursing 2013;69(2):363-373. doi: 10.1111/j.13652648.2012.06014.x 